\title{
Numerical investigation of the effect of beam slab openings in RC structures on seismic behavior
}

\author{
Ahmet Özbayrak*®i] 1 , Fatih Altun $\mathbb{1}$ \\ 1 Faculty of Engineering, Department of Civil Engineering, Erciyes University, Kayseri (Turkey), ozbay- \\ rak@erciyes.edu.tr; faltun@erciyes.edu.tr \\ *Correspondence: ozbayrak@erciyes.edu.tr
}

Received: 04.02.2021; Accepted: 22.12.2021; Published: 31.12.2021

Citation: Özbayrak, A. and Altun, F. (2021). Numerical Investigation of the Effect of Beam Slab Openings in RC Structures on Seismic Behavior. Revista de la Construcción. Journal of Construction, 20(3), 512-530. https://doi.org/10.7764/RDLC.20.3.512.

\begin{abstract}
Earthquake negatively affects the behavior of reinforced concrete frame systems that have slab discontinuities. As a result of differences in diaphragm behavior according to slab void ratio and position, lateral loads cannot be distributed to vertical bearing elements in proportion to their rigidity. In this study, the topic of differences in the behavior of reinforced concrete frame system under lateral load if void ratio and position of the slab change have been examined numerically. For this purpose, five single-story three-dimensional carrier frame models with different void ratios and positions were created in the ANSYS program analyzing according to the finite element method. As a result of the study, an increase in slab void ratio of reinforced concrete frame type carrier systems resulted in displacement in more significant amounts. Along with $25 \%$ being a safe void ratio in terms of rigid diaphragm behavior when the void ratio is $50 \%$, whether the void is symmetrical or not becomes extremely important in terms of behavior.
\end{abstract}

Keywords: Finite element method, Seismic effect, Slab discontinuities, Diaphragm behavior, Reinforced frame system.

\section{Introduction}

Earthquakes are possible lateral loads affecting the structure throughout its life. If necessary, precautions are not taken in selecting the carrier system; there are undesired earthquake damages even regarding the effects of small earthquakes. In case of the effects of devastating earthquakes, collapse mechanisms that are life-threatening emerge. Regulations in which the characteristics of the carrier system related to the earthquake are specified ensure that projected structures will behave as expected during an earthquake and no lives will be lost. For this, the diaphragm behavior should be accurately determined according to slab voids in the formation of the carrier system. One of the factors affecting this behavior is the discontinuities in reinforced concrete slabs. In earthquake regulations globally, for slabs to exhibit rigid diaphragm behavior, the ratio of the void area to the gross slab area is defined at different values (Table 1). This rate was $33 \%$ in the Turkish Buildings Earthquake Code, 20\% in Eurocode8, while it was 50\% in IBC2009 (Eurocode-8, 2005; IBC, 2009; TBEC, 2018). Due to differences in specifications up to $30 \%$, a numerical study has been carried out in the ANSYS program.

Table 1. Limiting states related to $A_{2}$ slab discontinuities in different country regulations (IAEE, 2000)

\begin{tabular}{|c|c|c|c|c|c|}
\hline Eurocode 8 & $\% 20$ & Canada & $\% 20$ & Iran & $\% 50$ \\
\hline India & $\% 20$ & Costa Rica & $\% 30$ & IBC 2009 & $\% 50$ \\
\hline Japan & $\% 20$ & Turkey & $\% 33$ & Korea & $\% 50$ \\
\hline
\end{tabular}


Studies on carrier systems with slab discontinuities have been examined in the literature regarding this topic (Özbayrak, 2017; Özbayrak \& Altun, 2020, 2021; Timoshenko, S. P., \& Woinowsky-Krieger, 1959; Timoshenko, S. P. and Goodier, 1970; Ugural, 1999; Volterra, E. and Gaines, 1971). Accordingly, the actual classification of structures revealed that the elasticity effect of slabs should not be neglected in the narrow and long buildings slabs, horizontally T-shaped and L-shaped buildings and similar buildings (Kunnath, Panahshahi, \& Reinhorn, 1991). The rigid diaphragm assumption yielded promising results in framed buildings; however, if the reinforced concrete shear walls are part of the carrier system, their section effect distribution varies (Saffarini \& Qudaimat, 1992). On buildings with shear walls in their load-bearing systems, rigid and elastic slab analyses showed that shear wall systems lead to different cross-section impact distribution on the floor as they have very high lateral rigidity (Ju \& Lin, 1999). It was analytically shown that the design rules in the current regulations are based on the behavior of rigid diaphragm structures, and they cannot adequately respond to different demands. Therefore, it has been proposed that new or modified design specifications for these structures should be created according to frame, shear-wall and discontinuity states (Fleischman \& Farrow, 2001). As a result of numerical solutions, it is suggested that the void ratio in the regulation should be reduced from $1 / 3$ to $1 / 5$ for non-symmetrical voids in buildings. It is recommended to leave dilatation in structures where it is obligatory to leave asymmetrical voids above 1/5 (Özsoy \& Kuyucular, 2003).

It has been revealed that the largest torsions occur in structure in which slab discontinuity is not symmetrically placed. For this reason, lateral displacements occur at larger values. Besides, the void ratio is large, especially the symmetry in the structure, which is more determinative for slabs to work as a rigid diaphragm (Arslan, 2007). It has been determined that the irregularities arising from the slab openings created at the corners of the buildings cause great stress. Therefore, it is recommended to arrange the openings to avoid disturbing the symmetry of the building and avoid creating slab openings in the corner areas (Yön, Öncü, \& Of, 2010). Concerning the slab behaving as a rigid diaphragm, the void ratio must be symmetrical besides the fact that it does not exceed the limiting value in the regulation. It has been emphasized that the greatest torsional effects occur in the buildings in which slab voids are not symmetrical, beams do not maintain continuity in these areas, and lateral displacements increased (Öztürk, 2013). Depending on the location and size of the slab openings, the collapse mechanism varies considerably compared to slabs without openings. It has been determined that the collapse hinges formed as a result of the yield of reinforcements at the edges of the slab opening significantly affect the slab behavior (Keyvani \& Hoseini Vaez, 2019). Slab discontinuities that disrupt the integrity of the structures cause problems in the transfer of seismic effects to the load-bearing elements. According to the analysis results, the dynamic envelopes obtained from the irregular building models exceed the dynamic envelope of the normal building for the $\mathrm{x}$ and $\mathrm{y}$ directions. This indicates that such irregularity causes greater shear force (Sağlıyan \& Yön, 2018). Results implicated that presence of openings clearly changed the in-plane behavior of RC slabs compared to those of slabs without openings and that this oversimplification in design and analysis of slabs by ignoring the opening effects might lead to erroneous results (Khajehdehi \& Panahshahi, 2016).

The originality of the present study is that, unlike the studies in the literature, the void ratio, and the effect of void position on the earthquake behavior were taken as basis. For reinforced concrete slabs to exhibit rigid diaphragm behavior, there have been attempts to determine the ratio of the slab void. In addition, frame system models have been created by considering the effect of void position in rigid diaphragm behavior. As a result of the study, it has been numerically revealed whether lateral loads can be distributed in proportion to the rigidity of columns due to the diaphragm behavior of slabs under the influence of earthquake by considering their states of stress. Accordingly, the rigid diaphragm behavior of frame system slabs with a $50 \%$ void ratio varied depending on the void location rather than the void ratio.

\section{Materials and methods}

\subsection{Numerical models}

The load and material assumptions made in numerical analyses and the realization of these assumptions in earthquake behavior significantly affect the accuracy of the results. The ANSYS program we have used in the study is software used in engineering, which calculates according to the finite element method. The program's most important feature is that it can carry out linear and nonlinear static and dynamic analysis without any limitations on the solution of models (Ansys Inc., 2013). Our 
numerical models were three-dimensional, $1 / 2$ scale, beam-slab, two-span, and single-story reinforced concrete frame systems with five different slab void ratios. The void-free test sample geometric measurements are given in Figure 1.

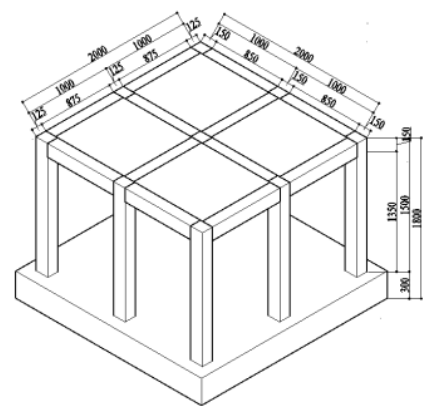

Figure 1. Carrier system geometry (mm).

There is no slab void in the frame system of the 1st model, which has been designed as a reference for the study. In addition, the 2nd sample, in which rigid diaphragm behavior was researched, was modeled as a three-dimensional model with $25 \%$ void, the 3rd and 4th samples with 50\% void (symmetric and asymmetric voids), and the 5th sample with 75\% void (Fig. 2).

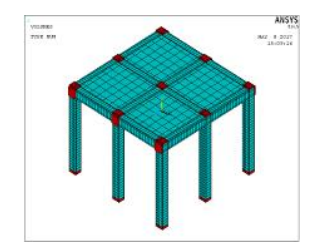

(a)

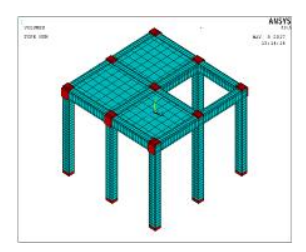

(b)

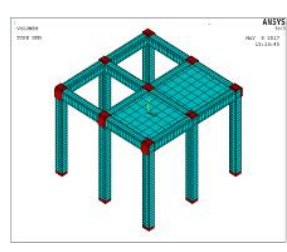

(c)

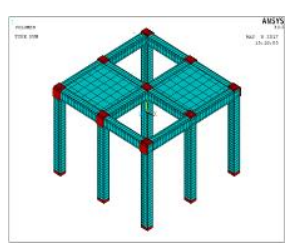

(d)

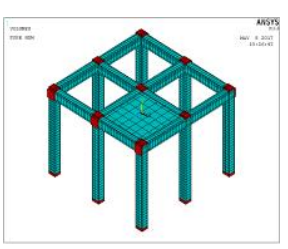

(e)

Figure 2. Numerical models (a) model 1 (reference); (b) model 2 (25\% openings); (c) model 3 (50\% openings); (d) model 4 (50\% openings); (e) model 5 (75\% openings).

\subsection{Scaling method}

In reinforced concrete models, the structural geometry, material and load properties were converted into $1 / 2$ scale by using the scale factors proposed by Harris and Sabnis (Harris \& Sabnis, 1999). The selected concrete class was used as C35 and reinforcement quality as S420 in the design of the models (TS500, 2000). Reinforcement diameters used in carrier systems are $\varnothing 4, \varnothing 6$ and $\emptyset 8 \mathrm{~mm}$. Scaling values for the numerical model are given in Table 2.

Table 2. Scaling of numerical models

\begin{tabular}{|c|c|c|}
\hline 1/1 Scale & Geometry / Materials / Load Properties & $1 / 2$ Scale \\
\hline $4800 \times 4800 x 60$ & Basic dimensions (mm) & $2400 \times 2400 \times 30$ \\
\hline$\varnothing 16 / 20$ & Base reinforcement $\left(\mathrm{mm}^{2}\right) \rho=0.00175$ & $\varnothing 8 / 10$ \\
\hline $250 \times 300$ & Column dimensions (mm) & $125 \times 150$ \\
\hline $250 \times 300$ & Beam dimensions (mm) & $125 \times 150$ \\
\hline 100 & Slab thickness (mm) & 50 \\
\hline 300 & Floor height (mm) & 150 \\
\hline C35-S420 & Concrete and reinforcement class & C35-S420 \\
\hline $924 \mathrm{~mm}^{2} / 6 \varnothing 14$ & Column reinforcement area $\rho=0.0123$ & $231 \mathrm{~mm}^{2} / 4 \varnothing 8+2 \varnothing 6$ \\
\hline $226 \mathrm{~mm}^{2} / 2 \varnothing 12$ & Beam reinforcement area $\rho=0.003$ & $56.5 \mathrm{~mm}^{2} / 2 \varnothing 6$ \\
\hline $500 \mathrm{~mm}$ & Column stirrup upper densification region height & $250 \mathrm{~mm}$ \\
\hline $790 \mathrm{~mm}$ & Column stirrup lower densification region height & $395 \mathrm{~mm}$ \\
\hline $1410 \mathrm{~mm}$ & Column stirrup centre Point height & $705 \mathrm{~mm}$ \\
\hline$\varnothing 8 / 80$ & Column stirrup densification reinforcement & $\varnothing 4 / 40$ \\
\hline $120 \mathrm{~mm}^{2} / \varnothing 8 / 120$ & Column stirrup centre point reinforcement & $60 \mathrm{~mm}^{2} / \varnothing 4 / 60$ \\
\hline$\varnothing 8 / 80$ & Beam stirrup densification reinforcement & $\varnothing 4 / 40$ \\
\hline $335 \mathrm{~mm}^{2} / \varnothing 8 / 300$ & Slab reinforcement area $\left(\mathrm{mm}^{2}\right) \rho=0.0028$ & $83.75 \mathrm{~mm}^{2} / \varnothing 4 / 150$ \\
\hline $176.2 \mathrm{kN}$ & Total structure weight & $43.7 \mathrm{kN}$ \\
\hline
\end{tabular}




\subsection{Material properties}

Three different materials were used in the ANSYS program to define the model element properties. SOLID65 for concrete, LINK180 for reinforcement, and SOLID185 for bearing and loading plates (Çelik, 2019). The stress-deformation curves obtained from the material tests were used to define the elastic and inelastic properties of the materials. C35 Concrete was subjected to pressure and tensile splitting tests, and the modulus of elasticity of the concrete was found to be $33953 \mathrm{~N} / \mathrm{mm}^{2}$ (Özbayrak, 2017). To determine the behavior of concrete after cracking, it is assumed that the shear force is transferred at $50 \%$ in open cracks by taking the shear force transfer coefficient for open cracks as 0.5 . As for closed cracks, it is assumed that shear force is completely transferred in closed cracks by taking the coefficient as 1 . Uniaxial tensile strength of concrete was used as $4.12 \mathrm{~N} / \mathrm{mm}^{2}$ in the program. The uniaxial compressive strength was assumed to be -1 and crushes in the concrete were ignored. Elastic and inelastic properties of the reinforcements defined in the program were found by tensile test and the stress-deformation behavior of each one was defined (Fig. 3).

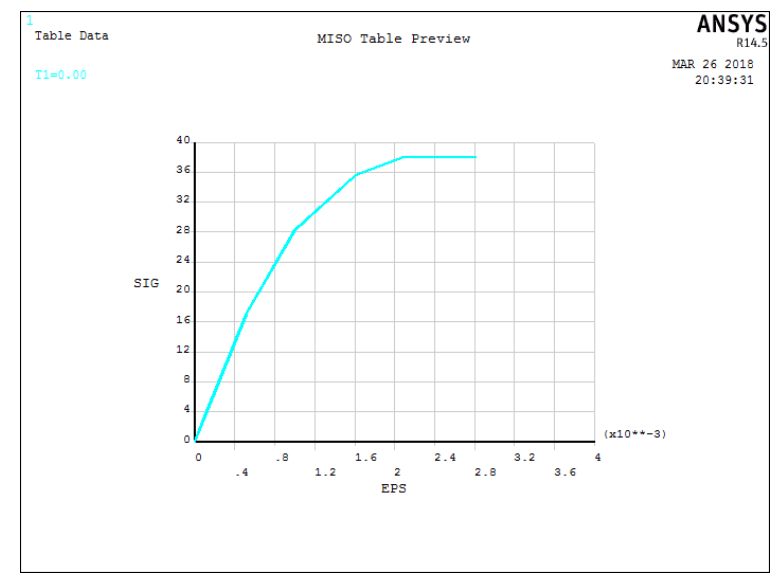

(a)

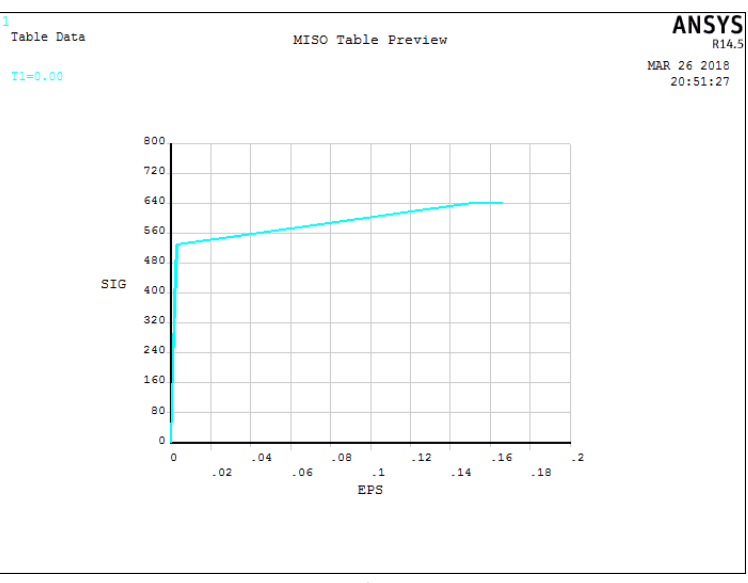

(b)

Figure 3. Defining the inelastic properties of materials [(a): concrete, (b): reinforcement]

The model is divided into mesh elements so that analysis can be done according to the finite element method. The mesh dimension found suitable for concrete and reinforcements is $25 \mathrm{~mm}$. However, because of the concrete cover in the study, reinforcements were placed $12.5 \mathrm{~mm}$ inside from the concrete shell. Thus, concrete shell mesh size is $12.5 \mathrm{~mm}$; the mesh operation was performed as $25 \mathrm{~mm}$ in other parts (Fig. 4).
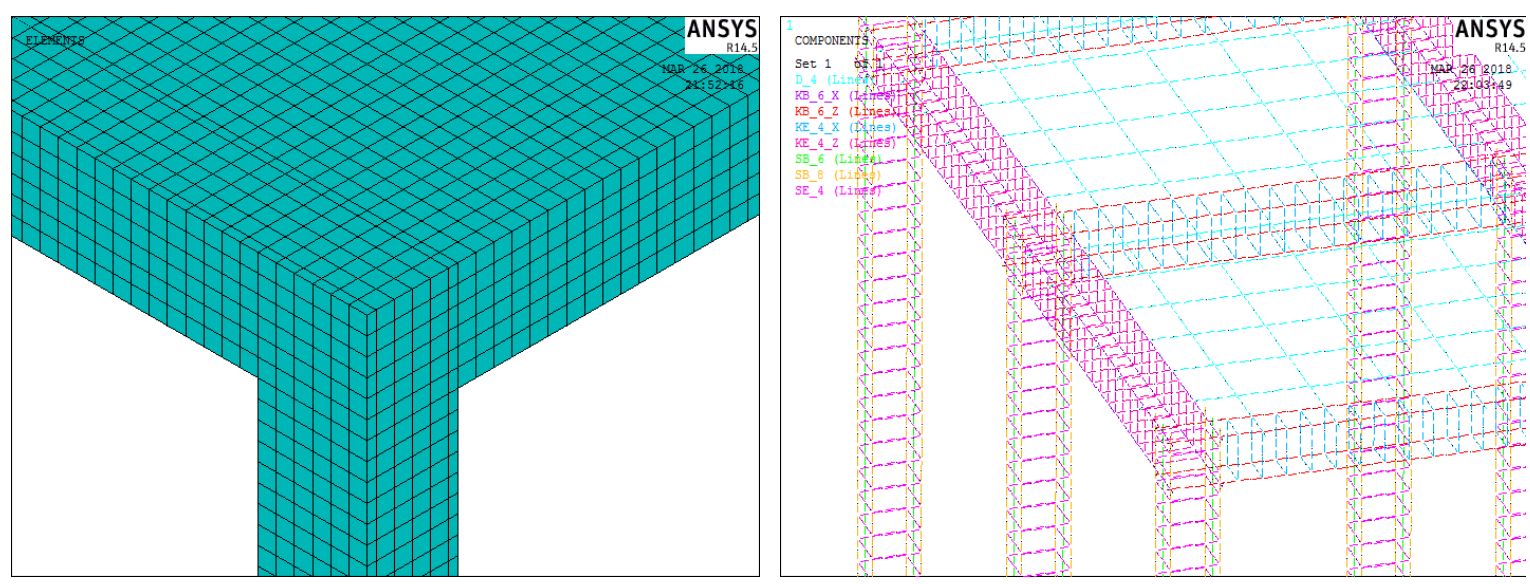

Figure 4. Mesh operation in concrete and reinforcement. 
Material type and properties were also assigned to the elements selected by mesh operation. First, the element type was determined as SOLID65 before the mesh was made to the selected volumes. Thus, after the mesh operation, all selected elements have gained concrete properties. After the reinforcement with three different diameters and strengths defined as LINK180 element has been assigned to the selected lines according to reinforcement diameters, separate mesh operations were performed for each type of reinforcement (Çelik, 2020). Fixed supports where rotation and drift are held in the directions of $\mathrm{x}, \mathrm{y}, \mathrm{z}$ were defined under the column base plate.

\subsection{Loading and analysis}

The loads defined in the ANSYS program have been affected in the form of cyclic reversible loading. In one of the studies in the literature, e.g. Verderame, De Risi, \& Ricci, (2018), the loading procedure consisted of displacement-controlled steps beginning at a $0.25 \%$ drift followed by steps of $0.50 \%, 0.75 \%, 1.00 \%, 1.50 \%, 2.00 \%, 3.00 \%, 4.00 \%$ and $6.00 \%$ drift. Each drift step consisted of three cycles of push and pull. However, the loading procedure used in this study is as given in Table 3 . Frame system columns have been subjected to a compressive load of at least $10 \%$ of their axial load carrying capacity during the analysis.

Table 3. Time-dependent load of the reference model.

\begin{tabular}{|c|c|c|c|c|c|c|c|}
\hline Cycle & Load $(\mathrm{kN})$ & Step & Sub step & $\begin{array}{l}\text { Time at End } \\
\text { of Load Step }\end{array}$ & $\begin{array}{c}\text { Time Step } \\
\text { Size }\end{array}$ & $\begin{array}{l}\text { Min. Time } \\
\text { Step }\end{array}$ & $\begin{array}{l}\text { Max. Time } \\
\text { Step }\end{array}$ \\
\hline 0 & $\begin{array}{c}\left(0.1 \mathrm{xA}_{\mathrm{c}} \mathrm{xf} \mathrm{f}_{\mathrm{ck}}\right) \\
\text { Axial }\end{array}$ & 1 & 9 & 25 & 5 & 2.5 & 10 \\
\hline \multirow{2}{*}{1} & 10 Lateral & 2 & 9 & 50 & 5 & 2.5 & 10 \\
\hline & -10 Lateral & 3 & 9 & 75 & 5 & 2.5 & 10 \\
\hline \multirow{2}{*}{2} & 20 Lateral & 4 & 39 & 175 & 5 & 2.5 & 10 \\
\hline & -20 Lateral & 5 & 39 & 275 & 5 & 2.5 & 10 \\
\hline \multirow{2}{*}{3} & 30 Lateral & 6 & 100 & 375 & 1 & 1 & 5 \\
\hline & -30 Lateral & 7 & 100 & 475 & 1 & 1 & 5 \\
\hline \multirow[b]{2}{*}{4} & 40 Lateral & 8 & 135 & 610 & 1 & 1 & 5 \\
\hline & -40 Lateral & 9 & 135 & 745 & 1 & 1 & 5 \\
\hline \multirow{2}{*}{5} & 50 Lateral & 10 & 170 & 915 & 1 & 1 & 5 \\
\hline & -50 Lateral & 11 & 170 & 1085 & 1 & 1 & 5 \\
\hline \multirow{2}{*}{6} & 60 Lateral & 12 & 300 & 1235 & 1 & 0.5 & 5 \\
\hline & -60 Lateral & 13 & 300 & 1385 & 1 & 0.5 & 5 \\
\hline \multirow{2}{*}{7} & 70 Lateral & 14 & 350 & 1560 & 1 & 0.5 & 5 \\
\hline & -70 Lateral & 15 & 350 & 1735 & 1 & 0.5 & 5 \\
\hline \multirow{2}{*}{8} & 80 Lateral & 16 & 400 & 1935 & 1 & 0.5 & 5 \\
\hline & -80 Lateral & 17 & 400 & 2135 & 1 & 0.5 & 5 \\
\hline \multirow{2}{*}{9} & 90 Lateral & 18 & 450 & 2360 & 1 & 0.5 & 5 \\
\hline & -90 Lateral & 19 & 450 & 2585 & 1 & 0.5 & 5 \\
\hline \multirow{2}{*}{10} & 100 Lateral & 20 & 500 & 2835 & 1 & 0.5 & 5 \\
\hline & -100 Lateral & 21 & 500 & 3085 & 1 & 0.5 & 5 \\
\hline \multirow{2}{*}{11} & 105 Lateral & 22 & 530 & 3350 & 1 & 0.5 & 5 \\
\hline & -100 Lateral & 23 & 500 & 3600 & 1 & 0.5 & 5 \\
\hline \multirow{2}{*}{12} & 98 Lateral & 24 & 500 & 3850 & 1 & 0.5 & 5 \\
\hline & -99 Lateral & 25 & 500 & 4100 & 1 & 0.5 & 5 \\
\hline \multirow{2}{*}{13} & 96 Lateral & 26 & 500 & 4350 & 1 & 0.5 & 5 \\
\hline & -95 Lateral & 27 & 500 & 4600 & 1 & 0.5 & 5 \\
\hline \multirow{2}{*}{14} & 80 Lateral & 28 & 500 & 4850 & 1 & 0.5 & 5 \\
\hline & -87 Lateral & 29 & 500 & 5100 & 1 & 0.5 & 5 \\
\hline
\end{tabular}


The resulting file has been adjusted so that all solution outputs are recorded every 10 incremental steps. Incrementing the load at the defined time interval to reach its final value in the transient tab is ensured by selecting the ramped loading option. The choice of the method to solve the equation in the sol'n options tab was left to the program. During the solution, the equations were solved according to the sparse direct method of the program. In the nonlinear tab, the line search command was activated. In this way, the ANSYS program searches for alternative ways to find the roots of the data obtained from the nonlinear solution according to the Newton Raphson method as used by Bastos Martinelli \& Cassimiro Alves, (2020). The maximum number of iterations in the solution equations was taken as 120 in the study. In the adjustment of the convergence criteria, control was carried out based on force and displacement. Tolerance values should be kept as small as possible so that the results can be closer to reality. In the analyses with ANSYS, iterations continue until convergence is ensured. The convergence value in ANSYS is Toler*Value. Tolerance values are taken as $0.5 \%$ for the force and moment in the L2 norm in the research analyses; in addition to this value, $5 \%$ is considered acceptable for displacements depending on the L2 norm. The value is obtained by the sum of square roots of squares of unbalanced forces. If force and moment convergence criteria are redefined differently, the displacement control should be carried out. Force convergence control should always be defined to achieve equilibrium in the solution. It is generally more accurate to set the Tolerance to change convergence criteria and give default value. Minref represents the lowest possible value. Minref (default 0.001) should numerically represent zero. The minimum force is not applied if the minref is set equal to -1 (Ansys Inc., 2013).

\section{Numerical results and discussions}

An increase in slab void ratios causes cracks in columns, column beam joints, especially in beam web, and large-scale damage in reinforced concrete carrier systems. Cracks in red represent the stage at which concrete begins to crack (flexural cracks). Green-colored cracks represent the stage in which reinforcements yield and shear (diagonal) cracks occur with the effect of increasing loads. Cracks in blue represent the final breaking stage of the concrete and the stage at which compressive cracks appear just before the concrete collapses. Cracks occurring under the effect of lateral load are given on the numerical model (Fig. 5).

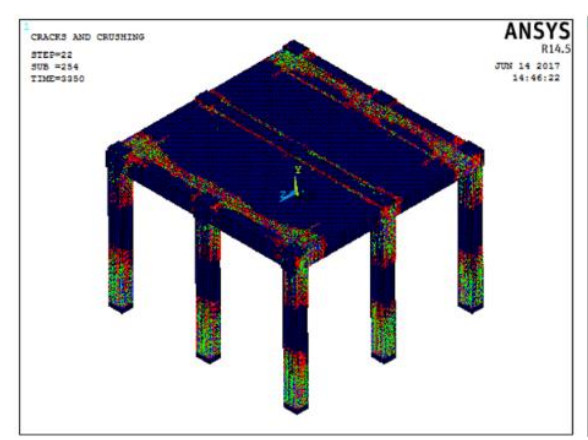

(a)

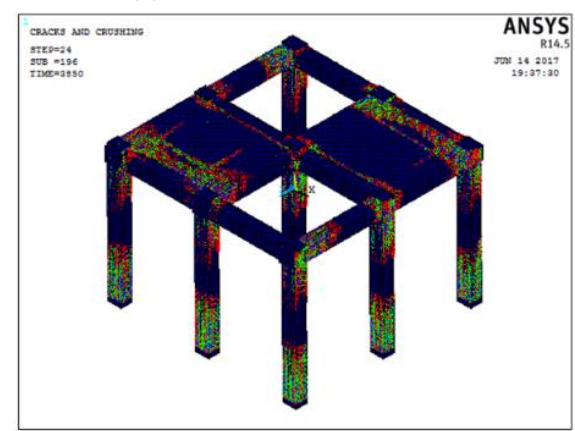

(d)

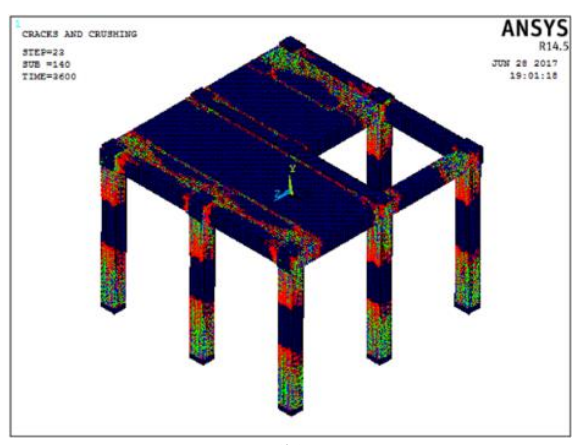

(b)

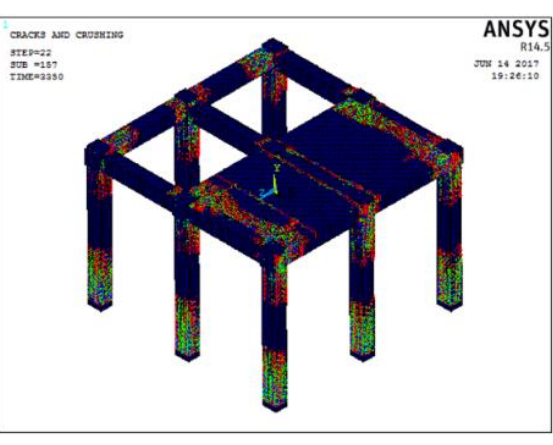

(c)

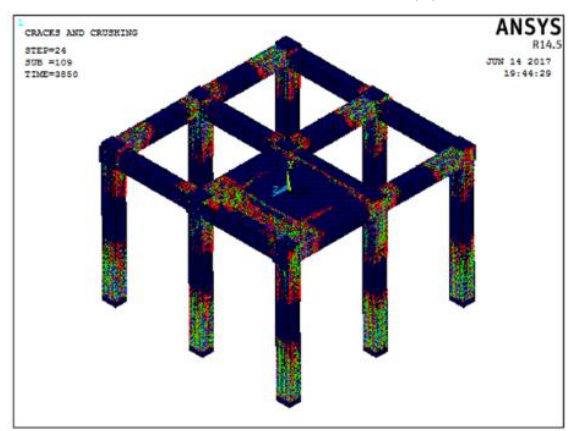

(e)

Figure 5. Cracks at the end of the numerical study (a) model 1; (b) model 2; (c) model 3; (d) model 4; (e) model 5. 
The displacement values formed by the force effect are compared with the reference model in the numerical models. For similar displacement values, the lateral load-carrying capacity of the models with slab voids decreased (Fig. 6). A comparison of numerical displacement results is given in the frame system for the selected $90 \mathrm{kN}$ lateral load value as a reference. In Table 4, it can be observed that slab discontinuities increased the carrier system displacements. As the void ratio increased, our models became more displacement. As a result of the comparison between the 3rd model with 50\% asymmetric void and the 4th model with 50\% symmetric void, it was observed that displacement values obtained from the 4th model yielded closer results to that of the 1 st model, which was the reference for the study. The 5 th model is the model that became the most dislocated and with the most negative results among all experiments. Compared to the reference model, there is a $17 \%$ difference in the displacement value. The closest results to the 1 st model were obtained from model 2 with $25 \%$ void and model 4 with $50 \%$ symmetric void.

Table 4. Comparison of numerical displacement capacities

\begin{tabular}{cccc}
\hline \multicolumn{3}{c}{ Table 4. Comparison of numerical displacement capacities } \\
\cline { 2 - 3 } Model name & \multicolumn{2}{c}{ Lateral load / displacement } & Displacement ratio \\
Model 1 & Ninth Cycle & $(\delta / \mathrm{H})$ & 1.00 \\
Model 2 & $90 \mathrm{kN}$ & 0.0059 & 1.05 \\
Model 3 & $90 \mathrm{kN}$ & 0,0062 & 1.10 \\
Model 4 & $90 \mathrm{kN}$ & 0.0065 & 1.03 \\
Model 5 & $90 \mathrm{kN}$ & 0.0061 & 1.17 \\
\hline
\end{tabular}

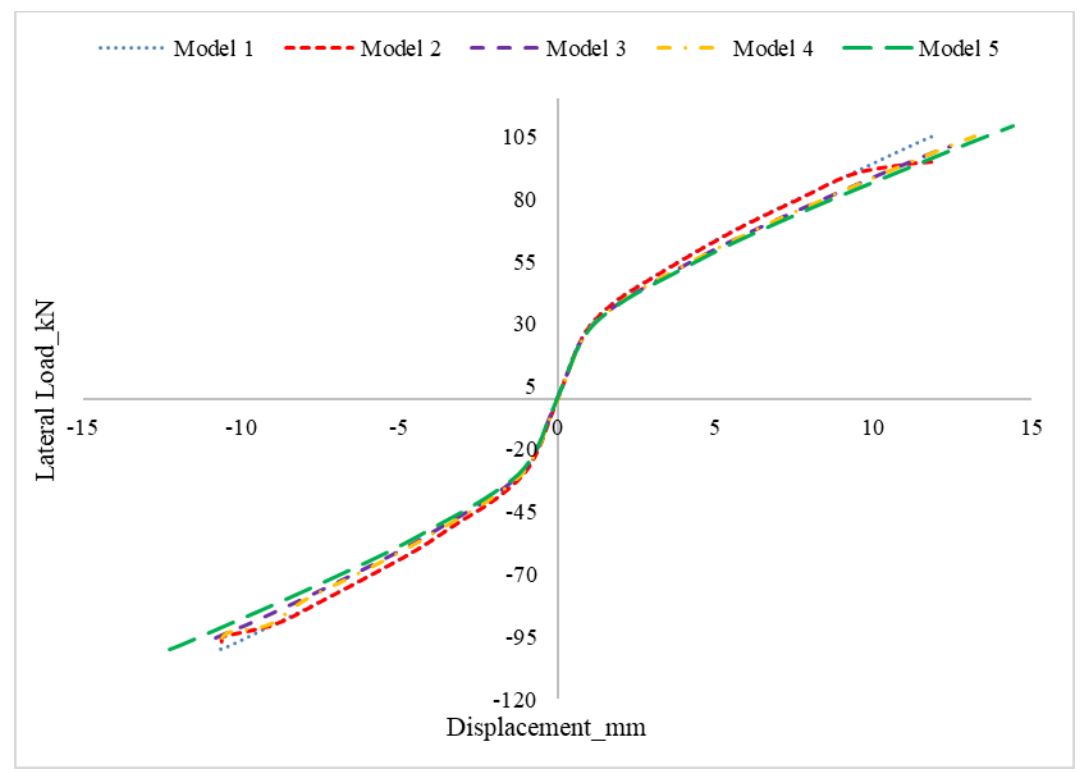

Figure 6. Numerical load-displacement envelope graphs.

According to the reference model in Table 5, the increase in the slab void ratio causes the rigidity of the frame system to decrease. In this case the most negative analysis result was obtained from the 5th model with $14 \%$. Although there was no difference in the first cycle rigidity, a difference of $3 \%$ occurred between the 3rd and 4th models under the influence of 90 $\mathrm{kN}$ (ninth cycle) lateral load. Accordingly, the 4th model with symmetric void yielded closer results to that of the reference model. As a result, the rigidity of the 2 nd and 4 th models exhibited closer behavior to that of the reference model (Fig. 7).

Table 5. Comparison of numerical stiffnesses

\begin{tabular}{ccccc}
\hline \multirow{2}{*}{ Model name } & \multicolumn{2}{c}{ Values of the stiffness $(\mathrm{kN} / \mathrm{mm})$} & $\begin{array}{c}\text { Ratio of first cycle } \\
\text { stiffness }\end{array}$ & $\begin{array}{c}\text { Ratio of ninth cycle } \\
\text { stiffness }\end{array}$ \\
\cline { 2 - 3 } Model 1 & First cycle & Ninth cycle & 1.00 & 1.00 \\
Model 2 & 33 & 9.88 & 1.00 & 0.96 \\
Model 3 & 33 & 9.55 & 0.97 & 0.91 \\
Model 4 & 32 & 9.01 & 0.97 & 0.94 \\
Model 5 & 32 & 9.28 & 0.94 & 0.86 \\
\hline
\end{tabular}




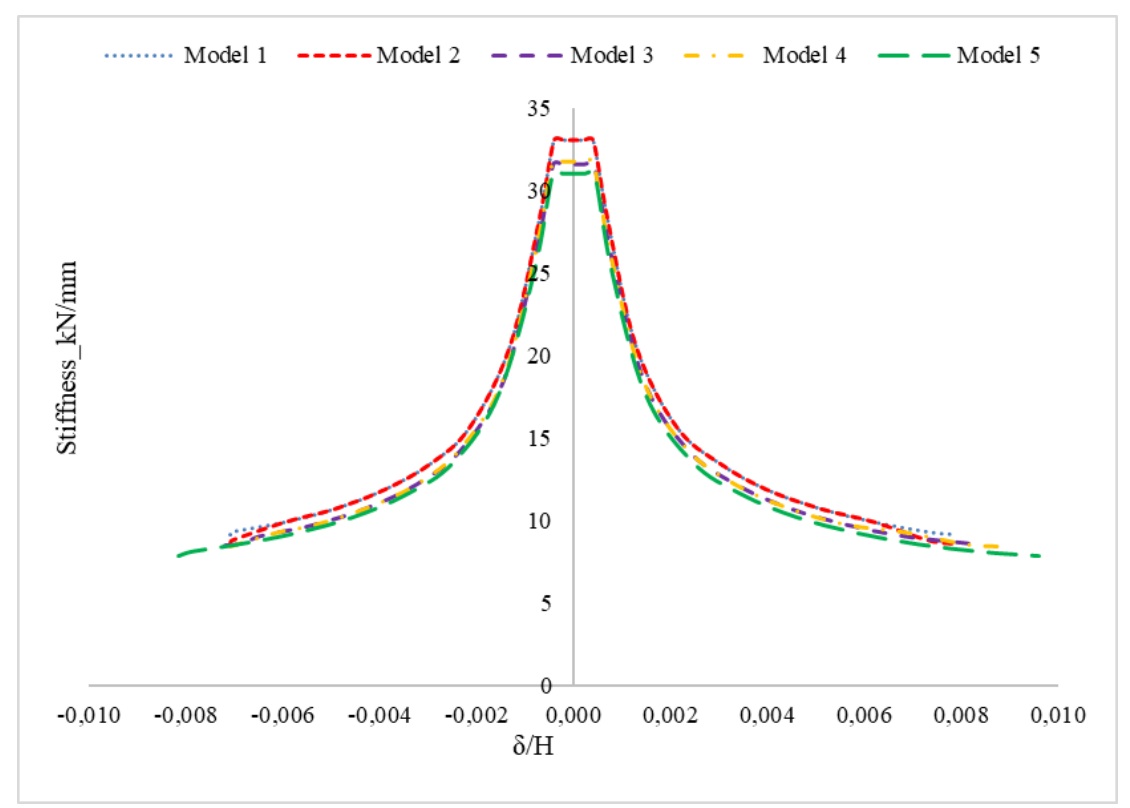

Figure 7. Decrement graphs of numerical stiffness.

Energy consumption values are calculated during the $90 \mathrm{kN}$ lateral load application to the frame system and are given in Table 6 . The second and fourth models yielded the closest results to the 1st model used as a reference. The close result of the 4 th model with a $50 \%$ void ratio to that of the 2 nd model with $25 \%$ void, was obtained due to the symmetrical placement of the voids in the 4th model. In the 3rd model with 50\% void, the resultant energy consumption was more significant because the voids were not symmetrical. The biggest difference from the reference model was observed in the 5th model with $75 \%$ void with a ratio of $16 \%$. The comparison between the 1 st model, which refers to operation, and the other frame system models is made in Figure 8.

Table 6. Comparison of numerical energy consumption capacities.

\begin{tabular}{ccccc}
\hline \multirow{2}{*}{ Model name } & \multicolumn{2}{c}{ Dissipated energy values $(\mathrm{kNmm})$} & \multicolumn{2}{c}{ Dissipated energy ratios } \\
\cline { 2 - 5 } Model 1 & Ninth cycle & Cumulative & Ninth cycle & Cumulative \\
Model 2 & 819 & 2384 & 1.00 & 1.00 \\
Model 3 & 849 & 2469 & 1.03 & 1.03 \\
Model 4 & 898 & 2621 & 1.09 & 1.10 \\
Model 5 & 872 & 2589 & 1.06 & 1.08 \\
\end{tabular}




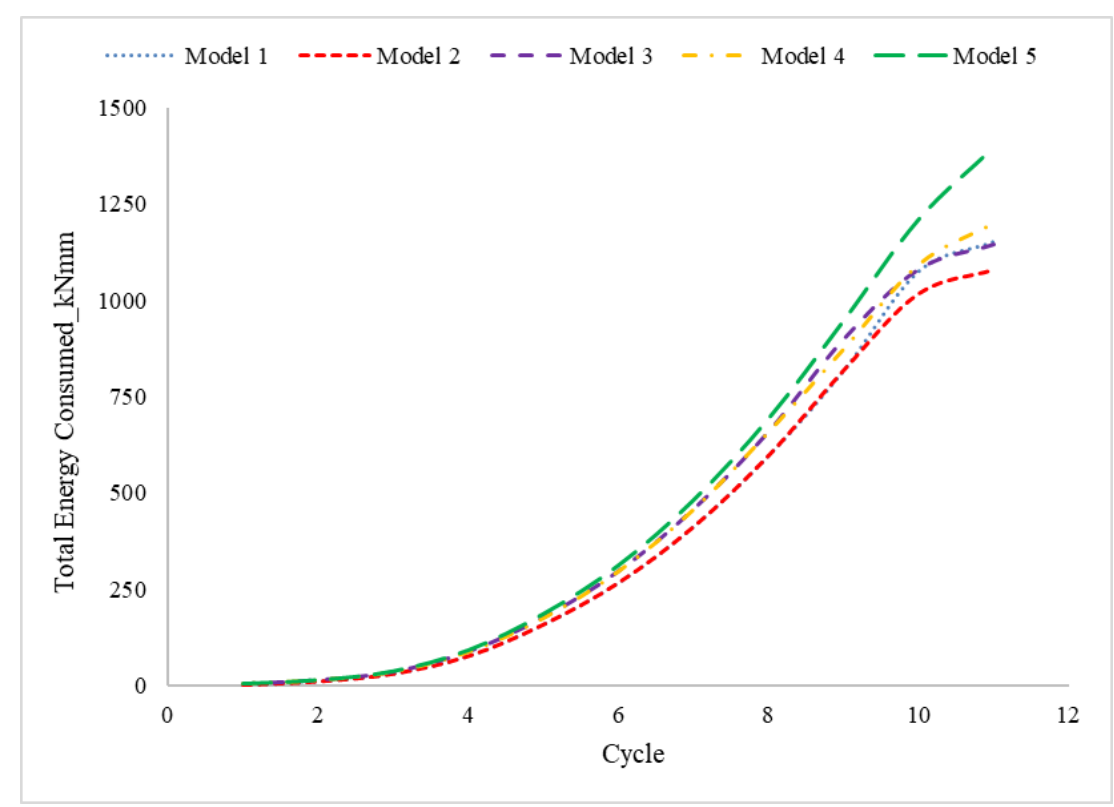

Figure 8. Numerical total consumed energy graphs

The closest results to the reference model regarding rigid diaphragm behavior was obtained from the 2nd model with $25 \%$ void and the 4th model with 50\% symmetric void. In 50\% slab void frame systems, the void position gains importance. Accordingly, if the weight and mass centers are overlapped, the behavior of the frame system with $50 \%$ void is observed as being close to that of the rigid diaphragm carrier system. Otherwise, irregular void distributions yielded more negative results for the $50 \%$ void ratio. Notable results were obtained when the void ratio increased to $75 \%$. Variations in the maximum and minimum displacement values in the directions of $\mathrm{x}, \mathrm{y}$, and $\mathrm{z}$ obtained from the numerical study are given for each model (Fig.9). The region where the displacements in the $\mathrm{x}$-x direction are the highest is seen in the parts without slab voids and where the lateral rigidity is higher. The most significant displacements in the (y-y) lateral load direction occurred in the beams located on the exterior axis in the areas with slab voids. Only Model 1 has a homogeneous distribution. In models with slab voids, especially in the third and fifth models, when the $\mathrm{x}$ and $\mathrm{y}$ directions are examined together, it is understood that torsion occurs. The only difference in vertical z-z direction displacements occurred in the exterior axis beams of Model 5, which had no slab void. Numerical results of displacements are shown in Table 7.
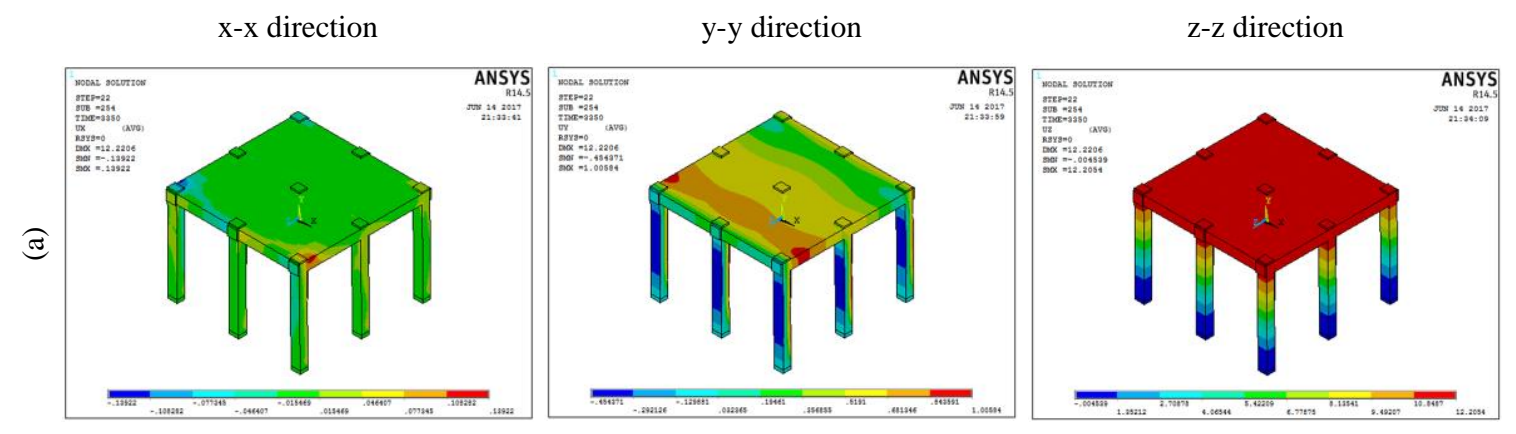

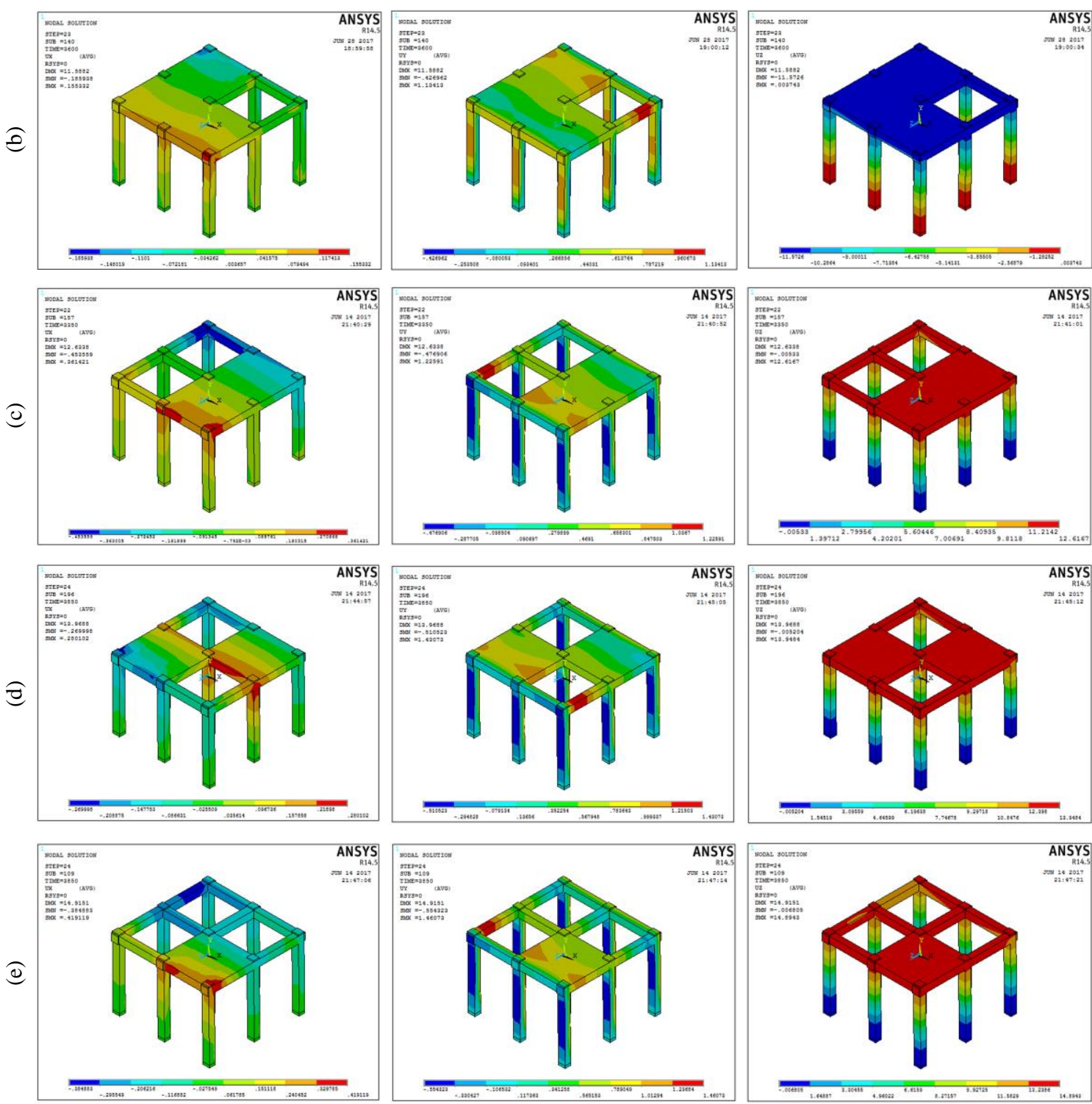

Figure 9. Maximum and minimum displacements in different axes (a) model 1; (b) model 2; (c) model 3; (c) model 4; (d) model 5.

The variations in maximum and minimum concrete stress values in the directions of $\mathrm{x}, \mathrm{y}$, and $\mathrm{z}$ obtained from the numerical study are given for each model (Fig. 10). Numerical results of stresses are summarized in Table 8. 

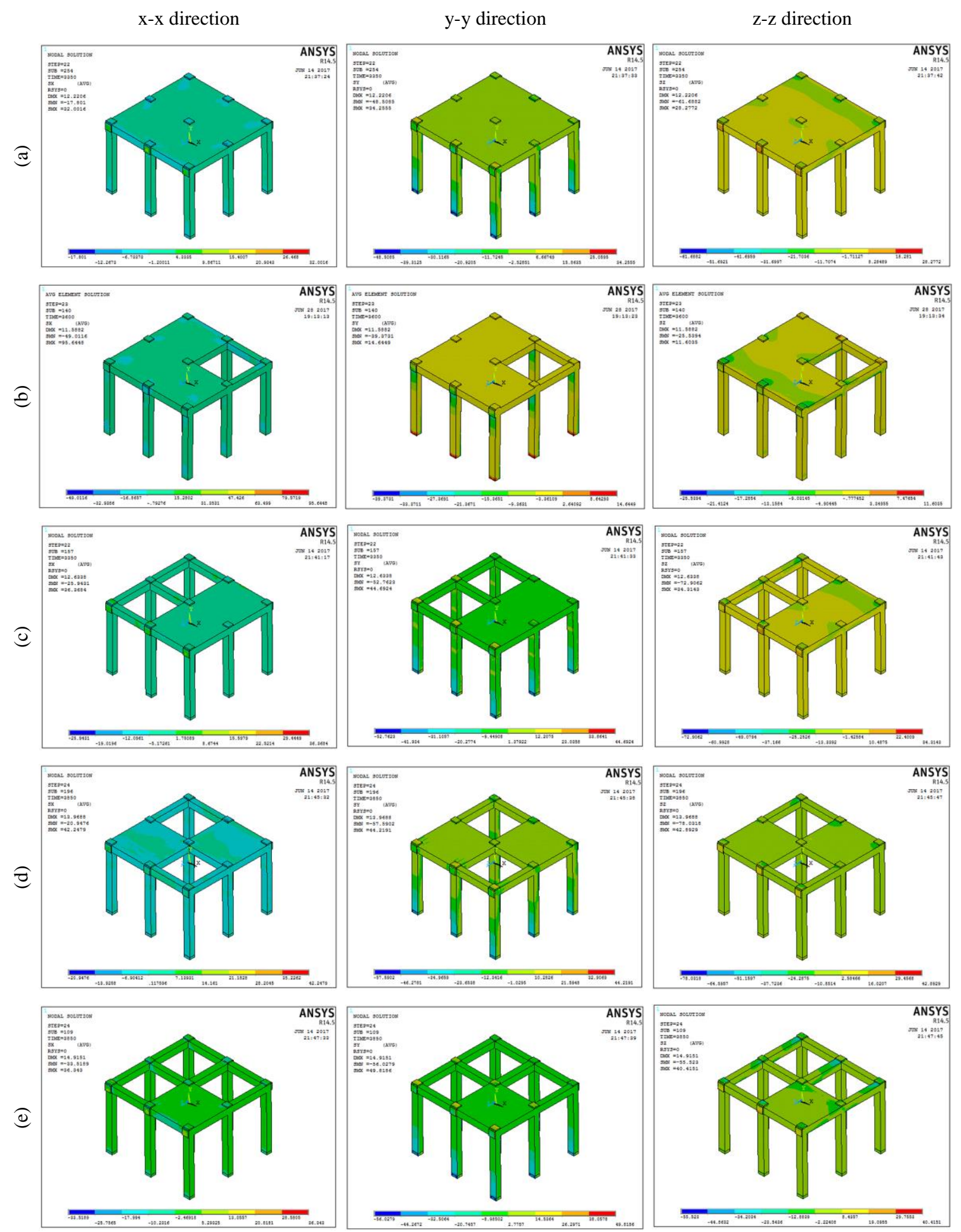

Figure 10. Maximum and minimum stresses in different axes (a) model 1; (b) model 2; (c) model 3; (d) model 4; (e) model 5.

The variations in the maximum and minimum stresses and unit deformation values of the reinforcement obtained from the analytical study are given for each model (Fig. 11). In Model 1 without slab void, the most stresses were observed in the column longitudinal reinforcements at the column-beam connections. However, in other models, the stresses at the column- 
beam joints on the slab void side are more concentrated in the beam longitudinal reinforcements than in the column longitudinal reinforcements. Numerical results of the reinforcements are given in Table 9.

Reinforcement stress
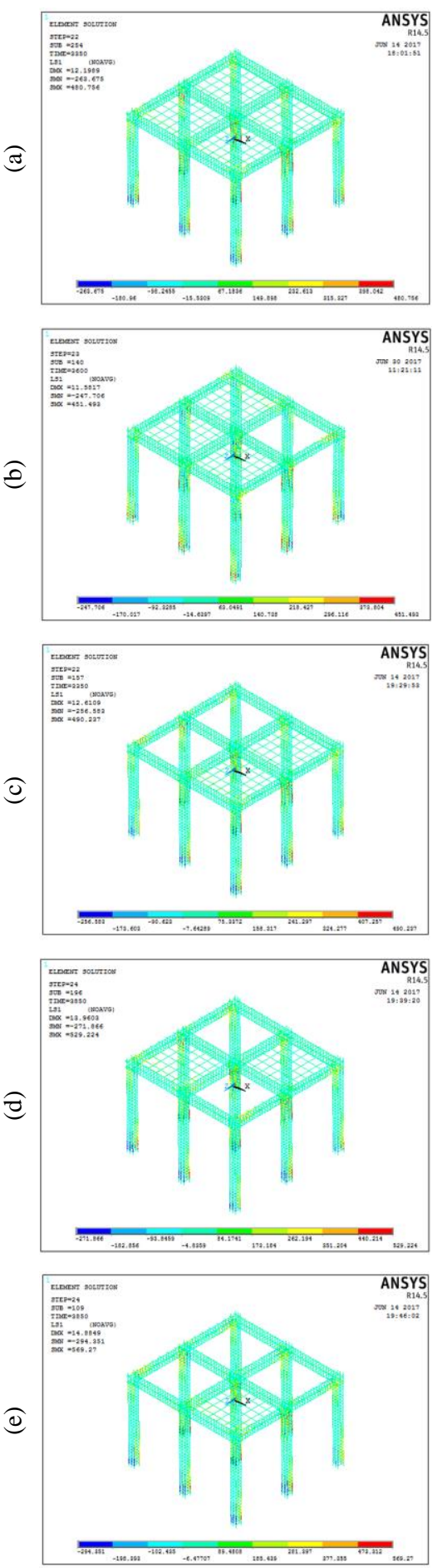
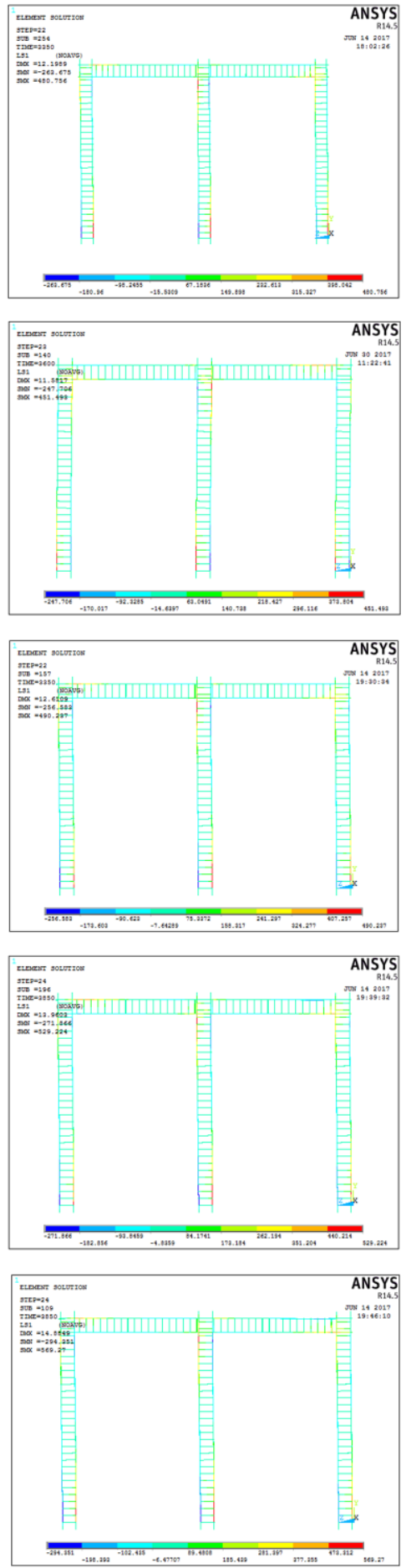

Reinforcement strain
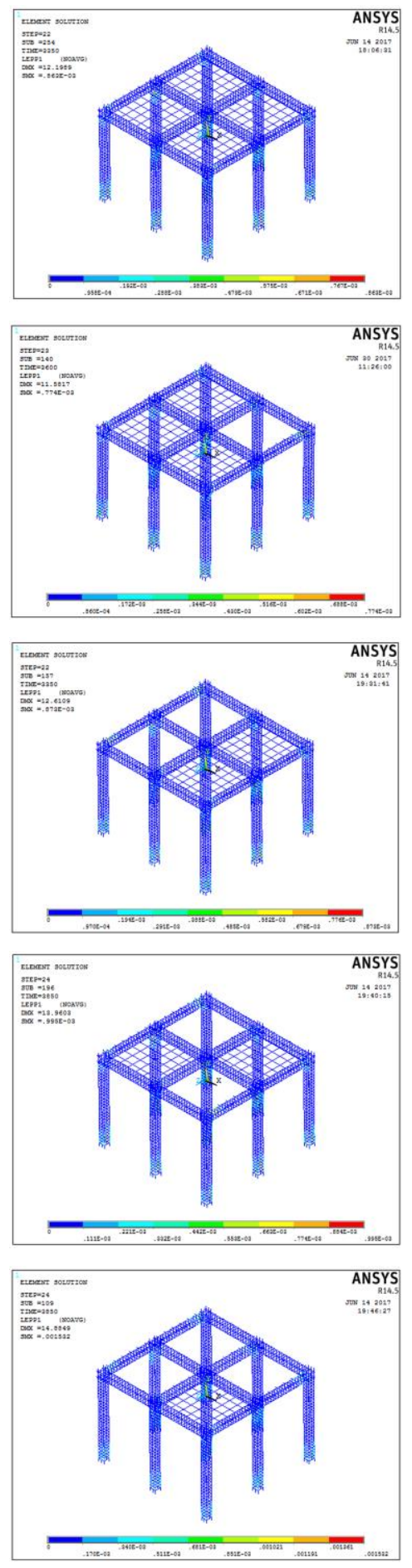

Figure 11. Variation of stress and unit deformations in reinforcements (a) model 1; (b) model 2; (c) model 3; (d) model 4; (e) model 5. 
When displacement values in general axes, stresses in reinforced concrete elements and stresses-deformations in the reinforcements are examined, the following results are obtained (Table 7, Table 8 and Table 9). According to the results summarizing numerical studies, if a closeness order is created for the reference test, the 2 nd model with $25 \%$ slab void is ranked first. After that, from the third and fourth models with 50\% slab voids, the first model is the 4th model with symmetrical slab void, and then the 3rd model with asymmetric slab void in the loading direction follows. Finally, the farthest results from the reference model were obtained from the 5 th model with $75 \%$ slab void.

Table 7. Numerical displacements of $90 \mathrm{kN}$ lateral load value $(\mathrm{mm})$.

\begin{tabular}{ccccccc}
\hline \multirow{2}{*}{$\begin{array}{c}\text { Model } \\
\text { name }\end{array}$} & \multicolumn{2}{c}{ X-X Direction } & \multicolumn{2}{c}{ Y-Y Direction } & \multicolumn{2}{c}{ Z-Z Direction } \\
\cline { 2 - 6 } Model 1 & Min. & Max. & Min. & Max. & Min. & Max. \\
Model 2 & -0.0707 & 0.0707 & -0.3635 & 0.7529 & -9.3159 & 0.0006 \\
Model 3 & -0.1381 & 0.1411 & -0.3828 & 0.9507 & -10.145 & 0.0021 \\
Model 4 & -0.1847 & 0.2506 & -0.3970 & 0.9425 & -10.214 & 0.0031 \\
Model 5 & -0.3493 & 0.1838 & -0.4170 & 1.1382 & -11.246 & 0.0040 \\
\hline
\end{tabular}

Table 8. Numerical stresses of $90 \mathrm{kN}$ lateral load value $\left(\mathrm{N} / \mathrm{mm}^{2}\right)$.

\begin{tabular}{|c|c|c|c|c|c|c|}
\hline \multirow{2}{*}{$\begin{array}{c}\text { Model } \\
\text { name }\end{array}$} & \multicolumn{2}{|c|}{ X-X Direction } & \multicolumn{2}{|c|}{ Y-Y Direction } & \multicolumn{2}{|c|}{ Z-Z Direction } \\
\hline & Min. & Max. & Min. & Max. & Min. & Max. \\
\hline Model 1 & -18.53 & 27.98 & -45.18 & 29.03 & -59.71 & 24.53 \\
\hline Model 2 & -19.53 & 28.23 & -47.42 & 29.87 & -62.49 & 34.77 \\
\hline Model 3 & -21.89 & 31.76 & -46.45 & 36.30 & -69.71 & 36.98 \\
\hline Model 4 & -19.49 & 29.59 & -44.97 & 32.65 & -66.97 & 33.53 \\
\hline Model 5 & -23.91 & 35.21 & -48.72 & 29.54 & -73.61 & 34.55 \\
\hline
\end{tabular}

Table 9. Numerical stresses-deformations of $90 \mathrm{kN}$ lateral load value $\left(\mathrm{N} / \mathrm{mm}^{2}\right)$.

\begin{tabular}{ccccccc}
\hline \multirow{2}{*}{$\begin{array}{c}\text { Model } \\
\text { name }\end{array}$} & \multicolumn{2}{c}{ Stress } & \multicolumn{2}{c}{ Strain $10^{-3}$} & \multicolumn{2}{c}{ Von Mises } \\
\cline { 2 - 6 } Model 1 & Min. & Max. & Min. & Max. & Min. & Max. \\
Model 2 & -217.7 & 398.6 & 0 & 0.617 & 0.042 & 102.1 \\
Model 3 & -223.7 & 411.1 & 0 & 0.652 & 0.034 & 106.7 \\
Model 4 & -230.9 & 423.2 & 0 & 0.680 & 0.031 & 114.7 \\
Model 5 & -221.4 & 396.0 & 0 & 0.671 & 0.036 & 110.3 \\
\hline
\end{tabular}

\section{Conclusions and comments}

The behavior of reinforced concrete three-dimensional frame systems under the effect of an earthquake has been examined depending on slab void ratios and void position. As a result of the numerical work carried out with the ANSYS program, displacements of reinforced concrete frame type bearing system in $\mathrm{x}, \mathrm{y}, \mathrm{z}$ directions, concrete stresses, reinforcement stresses, and reinforcement strains have been calculated. The results obtained from numerical evaluations based on these topics support each other.

As a result of the increase in slab void ratio of reinforced concrete frame type carrier systems, displacements occur in larger amounts. In general, the increase in void ratio increases energy consumption, increasing crack development in columns, column-beam joints and beam webs. Flexural cracks were first seen in the fourth cycle in the regions close to the lower and upper joints of the column. In the following cycles, these cracks gradually reached out towards the middle regions of the column. After the eighth cycle, shear cracks and concrete crushing occurred in the column-beam joints. In the eleventh cycle, the cracks in the column pushing and pulling faces extended to the column side faces and torsions occurred in the carrier systems. 
The formation of cracks on the lateral load direction and opposite faces of the load-bearing system columns indicated a torsional crack. Finally, cracks occurred in the slab on the lines where the beams supported the slabs (Fig.5).

As a significant result of this study, along with $25 \%$ being a safe void value in terms of rigid diaphragm behavior, void ratio, void position, and lateral loading direction should also be considered if the void ratio is $50 \%$. Thus, the results of reinforced concrete frames with 50\% slab void may be positive or negative in rigid diaphragm behavior. In the numerical results, if the structure mass and stiffness center do not overlap, since $50 \%$ slab voids cause torsions, leaving slab voids of $50 \%$ or greater is risky in terms of rigid diaphragm behavior in frame-type structures. In frame-type carrier systems with 50\% and over slab void, it is necessary to use the finite element method by considering the slab displacements. It is found to be a significant result to take the design of structures into account in terms of the behavior of structures against earthquakes.

Author contributions: Ahmet Özbayrak and Fatih Altun contributed to the design and implementation of the research, to the analysis of the results and to the writing of the manuscript.

Funding: This study was supported by the Department of Scientific Research Projects at Erciyes University with the project coded FDK-2016-6616.

Acknowledgments: This study was supported by the Department of Scientific Research Projects at Erciyes University with the project coded FDK-2016-6616.

Conflicts of interest: On behalf of all authors, the corresponding author states that there is no conflict of interest.

References

Ansys Inc. (2013). mechanical user's guide. ANSYS.

Arslan, S. (2007). Effects of the slab discontinuties on structural systems behavior in reinforcement buildings (Institute of Science and Technology). Institute of Science and Technology. Retrieved from https://polen.itu.edu.tr/handle/11527/6840

Bastos Martinelli, L., \& Cassimiro Alves, É. (2020). Analysis of damping ratio on the optimization of geometrically nonlinear truss structures subjected to dynamic loading. Revista de La Construcción. Journal of Construction, 19(3), 321-334. https://doi.org/10.7764/RDLC.19.3.321

Çelik, A. İ. (2019). Step by Step Finite Element Method with ANSYS Workbench (1st ed.; L. Gemi \& Y. O. Özkılıç, Eds.). Ankara: Nobel Bilimsel Eserler. Retrieved from www.nobelkitap.com

Çelik, A. İ. (2020). ANSYS WorkBench ile MEKANIK (1st ed.). Ankara: Nobel Bilimsel Eserler. Retrieved from www.nobelkitap.com

Eurocode-8, C. (2005). CEN (European Committee for Standardization). (2005).... - Google Akademik. Retrieved February 4, 2021, from European Committee for Standardization website: https://scholar.google.com/scholar?hl=tr\&as_sdt=0\%2C5\&q=CEN+\%28European+Committee+for+Standardization $\% 29 .+\% 282005 \% 29 .+$ Eurocode $+8 \% 3 \mathrm{~A}+$ Design+of+structures+for+earthquake+resistance-Part+1\%3A+General+rules $\% 2 \mathrm{C}+\mathrm{seismic}+\mathrm{ac}-$ tions+and+rules+for+buildings $\% 2 \mathrm{C}+$ Brusse

Fleischman, R. B., \& Farrow, K. T. (2001). Dynamic behavior of perimeter lateral-system structures with flexible diaphragms. Earthquake Engineering \& Structural Dynamics, 30(5), 745-763. https://doi.org/10.1002/eqe.36

Harris, H., \& Sabnis, G. (1999). Structural modeling and experimental techniques. Retrieved from https://books.google.com/books?hl=tr\&lr=\&id=_PQ1sAnCQxcC\&oi=fnd\&pg=IA5\&dq=Harris+HG.+and+Sabnis,+G.+(1999).+\&ots=_Ns0iAY4R7\&sig=mRH52fUAeCdOC649a4-OtaNXVIQ

IAEE. (2000). International Association for Earthquake Engineering. Retrieved February 4, 2021, from https://www.iaee.or.jp/worldlist.html

IBC. (2009). International Building Code.

Ju, S. H., \& Lin, M. C. (1999). Comparison of Building Analyses Assuming Rigid or Flexible Floors. Journal of Structural Engineering, 125(1), 25-31. https://doi.org/10.1061/(ASCE)0733-9445(1999)125:1(25)

Keyvani, S., \& Hoseini Vaez, S. R. (2019). Using DLO procedure to investigate the effect of openings on ultimate load and collapse pattern of slabs. Structures, 20, 717-727. https://doi.org/10.1016/J.ISTRUC.2019.06.023

Khajehdehi, R., \& Panahshahi, N. (2016). Effect of openings on in-plane structural behavior of reinforced concrete floor slabs. Journal of Building Engineering, 7, 1-11. https://doi.org/10.1016/j.jobe.2016.04.011

Kunnath, S. K., Panahshahi, N., \& Reinhorn, A. M. (1991). Seismic Response of RC Buildings with Inelastic Floor Diaphragms. Journal of Structural Engineering, 117(4), 1218-1237. https://doi.org/10.1061/(ASCE)0733-9445(1991)117:4(1218) 
Özbayrak, A. (2017). Özbayrak, A. (2017). Investigation of the effect... - Google Akademik. Retrieved February 4, 2021, from https://scholar.google.com/scholar?hl=tr\&as_sdt=0\%2C5\&q=Özbayrak\%2C+A.+\%282017\%29.+Investigation+of+the+effect+of+slab+discontinuities+on+earthquake+behavior+in+reinforced+concrete+structures $\% 2 \mathrm{C}+$ Doctoral+Thesis $\% 2 \mathrm{C}+$ Erciyes+University $\% 2 \mathrm{C}+\mathrm{Kayseri} . \& \mathrm{btnG}=$

Özbayrak, A., \& Altun, F. (2020). Torsional effect of relation between mass and stiffness center locations and diaphragm characteristics in RC structures. Bulletin of Earthquake Engineering, 18(4). https://doi.org/10.1007/s10518-019-00744-8

Özbayrak, A., \& Altun, F. (2021). Experimental study of the effects of slab openings on seismic behaviour of buildings. European Journal of Environmental and Civil Engineering, 1-21. https://doi.org/10.1080/19648189.2020.1868342

Özsoy, İ., \& Kuyucular, A. (2003). Influence of slab openings on floor displacements of reinforced concrete buildings beamed. Retrieved from https://www.imo.org.tr/resimler/ekutuphane/pdf/10128.pdf

Öztürk, T. (2013). Öztürk, T. (2013). Effect of openings in building... - Google Akademik. Retrieved February 4, 2021, from https://scholar.google.com/scholar?hl=tr\&as_sdt=0\%2C5\&q=Öztürk\%2C+T.+\%282013\%29.+Effect+of+openings+in+building+slabs+on+the+structural+system+behavior\%2C+Journal+of+IMO $\% 2 \mathrm{C}+393 \% 2 \mathrm{C}+6233-6256 . \& \mathrm{btnG}=$

Saffarini, H. S., \& Qudaimat, M. M. (1992). In-Plane Floor Deformations in RC Structures. Journal of Structural Engineering, 118(11), 3089-3102. https://doi.org/10.1061/(asce)0733-9445(1992)118:11(3089)

Sağliyan, S., \& Yön, B. (2018). Assessment of Earthquake Behavior of Reinforced Concrete Buildings with Slab Discontinuity. Turkish Journal of Science \& Technology, 13(1), 87-92.

TBEC. (2018). TBEC (Turkish Buildings Earthquake Code). (2018).... - Google Akademik. Retrieved February 4, 2021, from Turkish Buildings Earthquake Code website: https://scholar.google.com/scholar?hl=tr\&as_sdt=0\%2C5\&q=TBEC+\%28Turkish+Buildings+Earthquake+Code \%29.+\%282018\%29.+Specifications+for+the+buildings+to+be+constructed+in+disaster+areas\%2C+Ministry+of+Public+Works+and+Settlement\%2C+Ankara+\%28in+Turkish\%29\&bt

Timoshenko, S. P., \& Woinowsky-Krieger, S. (1959). Theory of plates and shells. McGraw-hill: McGraw-hill.

Timoshenko, S. P. and Goodier, J. N. (1970). Timoshenko, S. P. and Goodier, J. N. (1970). Theory... - Google Akademik. Retrieved February 4, 2021, from https://scholar.google.com/scholar?hl=tr\&as_sdt=0\%2C5\&q=Timoshenko\%2C+S.+P.+and+Goodier\%2C+J.+N.+\%281970\%29.+Theory+of+Elasticity $\% 2 \mathrm{C}+3 \mathrm{rd}+$ Edition. \&btnG=

TS500. (2000). TS500 (Turkish Standards Institute). (2000). Requirements... - Google Akademik. Retrieved February 4, 2021, from Turkish Standards Institute website: https://scholar.google.com/scholar?q=TS500+(Turkish+Standards+Institute).+(2000).+Requirements+for+Design+and+Construction+of+Reinforced+Concrete+Structures, + Ankara+(in+Turkish)\&hl=tr\&as_sdt=0,5

Ugural, A. (1999). Stresses in plates and shells. Retrieved from https://cds.cern.ch/record/465975

Verderame, G. M., De Risi, M. T., \& Ricci, P. (2018). Experimental Investigation of Exterior Unreinforced Beam-Column Joints with Plain and Deformed Bars. Journal of Earthquake Engineering, 22(3), 404-434. https://doi.org/10.1080/13632469.2016.1233917

Volterra, E. and Gaines, J. H. (1971). Volterra, E. and Gaines, J. H. (1971). Advanced strength... - Google Akademik. Retrieved February 4, 2021, from https://scholar.google.com/scholar?hl=tr\&as_sdt=0\%2C5\&q=Volterra\%2C+E.+and+Gaines\%2C+J.+H.+\%281971\%29.+Advanced+strength+of+materials $\% 2 \mathrm{C}+$ Prentice-Hall.\&btnG=

Yön, B., Öncü, M., \& Of, Z. U. (2010). Investigation of Effect of Slab Opening Location to the Shear Stress. Pamukkale University Journal. Retrieved from http://pajes.pau.edu.tr/eng/jvi.asp?pdir=pajes\&plng=eng\&un=PAJES-06978

(C) $\Theta \Theta \Theta$

Noncommercial-No Derivatives 4.0 International License. 